\title{
Pattern of Acute Poisoning Attending a Tertiary Care Hospital of Western Nepal
}

\author{
Raju Prasad Shakya, ${ }^{\mathrm{a}, \mathrm{c}}$ Suraj Adhikari, ${ }^{\mathrm{b}, \mathrm{c}}$ Rohit Bajracharya ${ }^{\mathrm{b}, \mathrm{c}}$
}

\begin{abstract}
:
Introduction: Poisoning with various substances is a major public health problem and a reason for significant morbidity and mortality throughout the globe. It is one of the most common presentation in an emergency department. This study was conducted to determine the sociodemographic, poisoning types, and mode of poisoning in cases attending a tertiary hospital of Western Nepal. Methods: A retrospective observational study of two years was conducted from July 2014 to June 2016. Demography details, name of poisonous substance, and reasons for poisoning were reviewed and analyzed using descriptive statistics. Results: A total of 65 cases of poisoning were recorded. The occurrence was more common in female $(n=44,67.7 \%)$ with a F:M ratio of 2.1:1. Poisoning was most common in the age group of $11-20$ years (32.3\%). Most of the cases were students (37\%) followed by farmers (26\%). The most commonly abused poisoning substance were organophosphorous compounds, zinc phosphide, and kerosene in adults, adolescents, and children respectively. Oral route was the most common (99\%) route of administration. Suicidal attempt, as a mode of poisoning, accounted for $70.8 \%$ of total poisoning cases. Conclusion: Female and young people are at greater risk of acute poisoning. Insecticide was the most common agent. The occurrence of poisoning and its morbidity and mortality can be reduced by development and implementation of effective prevention strategies like restricting easy access to poisons, establishing drug and poison information centers, and community awareness programs.
\end{abstract}

Keywords: organophosphate poisoning • poisoning • suicide

\section{INTRODUCTION:}

Poison may be defined as a substance which harms heath or destroy life when introduced in to the system or applied externally. ${ }^{1}$ Poisons are subtle and silent weapons, which can be easily used without violence and often without arousing suspicion. ${ }^{2}$ The global incidence of poisoning is not known. Recently some review articles reported that the number of intoxications with organophosphate pesticides was

a - Consultant Family Physician

b - Medical Officer

c - Department of Emergency

Lumbini Medical College Teaching Hospital, Palpa, Nepal

Corresponding Author:

Dr. Raju Prasad Shakya

e-mail: rajushakyaa@gmail.com

How to cite this article:

Shakya RP, Adhikari S, Bajracharya R. Pattern of acute poisoning attending a tertiary care hospital of western Nepal. Journal of Lumbini Medical College. 2016;4(2):90-3. doi: 10.22502/jlmc.v4i2.98. three million per year and the number of deaths and casualties are 3,00,000 per year worldwide. ${ }^{3}$

In Nepal, narcotic drug control Act 2038 and pesticide Act 2048 prohibits the misuse of narcotics and pesticides. However, improper implementation of these has lead to such problems. ${ }^{4}$ Poisoning is a medical emergency and a patient is always invariably rushed to the hospital at the earliest possible moment irrespective of the amount and nature of poison ingested. All the cases of poisoning are admitted through emergency service where the safety of life of the patient is the main issue for the doctor. ${ }^{5}$ The present study was conducted with the objective to investigate the pattern of acute poisoning cases in a teaching hospital in Western Nepal.

\section{METHODS:}

This hospital based retrospective, observational study was carried out in the emergency department of Lumbini Medical College Teaching Hospital, Palpa, Nepal during the period of two years 
from July 2014 to June 2016. Ethical clearance was approved from the institutional review committee of the institute. Medical records of all the poisoning cases during that period were studied and the findings were noted. Data regarding age, sex, occupation, history of psychiatric illness, reasons for exposure, and routes of exposure to the poison were obtained.

Patients with food poisoning, snake or insect bite, and those brought by police for the investigation of alcohol consumption were excluded. Data were entered into Microsoft Excel 2007 and analyzed with SPSS-21 software. Descriptive data were presented as frequency and percentage.

\section{RESULTS:}

A total of 65 cases of poisoning attended the emergency department during the study period of two years. The mean age of female was $28 \mathrm{yr}(S D=16.5)$ and male was $25.5 \mathrm{yr}(S D=13.8)$ with overall $\mathrm{F}: \mathrm{M}$ ratio of 2.01:1. Most cases $(n=21,32.3 \%)$ were in the age group of 11-20 year, followed by 16 (24.61\%) in 21-30 year. Ten (15.38\%) cases belonged to agegroup 21-30 year followed by six $(9.23 \%)$ cases in each of 1-10 year and 41-50 years. Thus the instances of poisoning decreased with increasing age beyond ten years of age.

Poisoning was most common among students. Occupation-wise distribution of frequency of poisoning is shown in Table 1. Forty-six (70.76\%) cases were of intentional poisoning whereas the rest $19(29.23 \%)$ were accidental. Among the intentional cases, domestic quarrel was the most common cause for poison consumption. Other causes of intentional poisoning is given in Table 2. Organophosphorus poisoning was the most common poison used. Other poison were as shown in Table 3. Most of the patients $(n=40,61.5 \%)$ obtained poison that was stored in home and the rest bought it from the market. All most all (99\%) poison were consumed orally. Less then half $(n=30,46.2 \%)$ of the cases had formal education whereas $19(29.2 \%)$ were literate without formal education and the rest $16(24.6 \%)$ were illiterate.

\section{DISCUSSION:}

Arrival of 65 cases of poisoning in the Emergency department of Lumbini Medical College over a period of two years emphasize the seriousness of the problem of poisoning in this area. Acute poisoning is an important clinical emergency and contributor to morbidity and morbidity. Early
Table 1: Occupation of the patients

\begin{tabular}{ccc}
\hline Occupation & $\boldsymbol{n}$ & $\boldsymbol{\%}$ \\
\hline Students & 24 & 36.92 \\
\hline Farmer & 17 & 26.15 \\
\hline Housewife & 14 & 21.53 \\
\hline Service holder & 4 & 6.15 \\
\hline Laborer & 2 & 3.07 \\
\hline Business-service & 1 & 1.53 \\
Other & 4 & 4.61 \\
\hline Total & $\mathbf{6 5}$ & $\mathbf{1 0 0}$ \\
\hline
\end{tabular}

Table 2: Reasons for intentional poison consumption

\begin{tabular}{ccc}
\hline Reasons & $\boldsymbol{n}$ & $\boldsymbol{\%}$ \\
\hline Domestic quarrel & 30 & 65.2 \\
Love /tragedy & 6 & 13 \\
To threaten Family & 5 & 10.9 \\
Financial & 5 & 10.9 \\
\hline Total & $\mathbf{4 6}$ & $\mathbf{1 0 0}$ \\
\hline
\end{tabular}

Table 3: Types of poison used

\begin{tabular}{|ccc}
\hline Poisons & $\boldsymbol{n}$ & \% \\
\hline Organophosphates & 21 & 32.31 \\
\hline Zinc Phosphide & 17 & 26.16 \\
\hline Dhatura (Belladona) & 11 & 16.93 \\
\hline Alcohol & 6 & 9.23 \\
\hline Paracetamol & 4 & 6.16 \\
\hline Phenol & 2 & 3.08 \\
\hline Antidepressant & 1 & 1.54 \\
Mushroom & 1 & 1.54 \\
\hline Kerosene & 1 & 1.54 \\
Acid & 1 & 1.54 \\
\hline Total & $\mathbf{6 5}$ & $\mathbf{1 0 0}$ \\
\hline
\end{tabular}

diagnosis, treatment and prevention are crucial in reducing the burden of poisoning-related injury in any country.

The present study revealed that the poisoning was more common in female compared to male (2.01:1). Similar finding was obtained in the study done in Bir hospital of Nepal with F:M ratio of $1.3: 1$ which is comparatively lower than ours and in another study in Oman. ${ }^{6,7}$ Another study done in Kathmandu Medical College revealed a lower than previous two studies F:M ratio of 1.09:1. ${ }^{8}$ Another study showed the ratio of 2:1 which was comprable to ours. ${ }^{9}$ A study done in university hospital emergency department in Turkey revealed F:M ratio of 3.5:1 which was much higher than ours. ${ }^{10}$ Female 
preponderance in this study could be accounted to the fact that females are often exposed to the stress and strain of day to day life in our society.

By age group, $32.3 \%$ of the patients were in 11-20 years and next $24.6 \%$ in $21-30$ years, implicating that patients between 11 to 30 years constitute the majority of the patients. This is the age of transition from childhood to adulthood, from immaturity to maturity; so, they are prone to psychological, cognitive, social, cultural, and emotional stress. They are less mature to cope these problems of life and may easily get carried away making suicide their last resort.

In our study, $36.92 \%$ of the patients were students, $26.16 \%$ were farmer, and $21.53 \%$ were housewife. Students were the most common group to consume poison followed by the housewives in a study in the capital city of our country. ${ }^{8}$ Poisoning was more prevalent among farmers in our study. This may be due to the fact that our centre is located in the rural hilly area of the country where the proportion of farmers are high. These groups are vulnerable for poisoning as they are under continuous financial and other stress during the life.

Regarding education, $29.23 \%$ of the cases were literate without formal education, $24.61 \%$ of the cases were illiterate and rests of them had formal education. Uneducated people comprised majority $(53.84 \%)$ of the poisoning cases. This can be explained by the fact that failure in life is more likely in uneducated people and they lack capacity to tolerate the problems due to the lack of education.

Majority of the cases $(70.67 \%)$ consumed poison intentionally and rest accidentally. A study done in Bir Hospital in the capital city revealed that ninety-seven cases $(98.0 \%)$ were intentional poisoning for suicidal attempt which is much higher compared to our study. ${ }^{6}$ Unintentional poisoning commonly resulted from intake of foods, especially mushroom, or was mistakenly taken as food or water under influence of alcohol. This may be due to fact that the life in capital city is difficult for those who are already facing problems in life. Indifferent attitude of its inhabitants, cost of living, and lack of time for themselves and their family can be some contributing factors. Again, intentional poisoning may be more common these days because a large group of people are victims of reactive depression and subjected to stress in academic, financial, and social sectors. ${ }^{11}$

Quarrel in the family was the most common cause $(70.76 \%)$ of intentional poisoning. Thus, misunderstanding at the family level has been the prime factor responsible for intentional poisoning.

Organophosphorus compound was the most common poison used and was found to be used in about a third $(32.3 \%)$ of the cases. Commonly used organophosphates were methyl parathion (Metacid) and dichlorovos (Nuvan). ${ }^{12}$ This is consistent with other studies carried out in Nepal. ${ }^{13-19}$ In a small study from eastern part of the country, $62 \%$ of poisoning patients consumed Metacid as poison. However, a study done in Turkey revealed that the most common substance used for self-poisoning were medicinal druges, antidepressants being the most common of them. ${ }^{10}$ This may be due to easy and wide-spread availability of organophosphates as insecticides in the rural part of our agricultural country. It was also found that accidental poisoning commonly resulted from intake of foods, especially mushrooms and dhatura (beladona). However, organophosphates are gradually replaced with phosphides and similar rodenticides due to their fast and more effective actions..$^{20}$

Among all the cases, $61.53 \%$ of the cases had poison stored in home. Agricultural insecticides are generally stored in every home as agriculture is one of the most common occupation of the people in our locality.

\section{CONCLUSION:}

We conclude that the poisoning is a common cause of hospital admission and a matter of concern in our place. Majority of them were intentional to harm oneself. Agricultural pesticides, which is common in our place, constitute the most common poison substance. Hence the pesticides must be sold in the presence of a witness who should be known to the clients. Family quarrel was the most common cause of poisoning and it can not be treated medically. Here comes the need for psychological evaluation and counseling which may minimize the risk of next attempt of self harm.

\section{REFERENCES:}

1. Bhoopendra S, Unnikrishnan B. A profile of acute poisoning at mangalore (south India). J Clin Forensic Med. 2006;13:112-6.
2. Pothireddy S, Mohanty MK. Study of poisoning cases in a tertiary care Hospital. JSIMLA. 2011;3:14-8. 
3. Harvey RA, Champe D. Lippincott's illustrated Reviews: Pharmacology, $4^{\text {th }}$ ed. USA: Lippincott Williams and Wilkins; 2009. 535 p.

4. Pokhrel D, Pant S, Pradhan A, Mansoor S. A comparative study of poisoning cases in central, zonal and district hospitals . KUJSET. 2008;5:40-8.

5. Dash SK, Raju AS, Mohanty MK, Patnaika KK, Siddharatha P, Mohanty S. Socioeconomic Profiles of Poisoning Cases. JIAFM. 2005;27:133-8.

6. Singh DP, Acharya RP. Patterns of poisoning in Nepal. J Inst Med. 2006;28:3-6.

7. Lal SB, AL-Wahaibi SS, Al-Riyam MM, Al-Kharusi K. Profile of acute poisoning cases presenting to health centres and hospitals in Oman Eastern. Mediterranean Health Journal. 2003;9:944-54.

8. Khadka SB, Ale SB. A study of poisoning cases in emergency Kathmandu Medical College Teaching Hospital. KUMJ. 2005;3:388-91.

9. Baydin A, Yardan T, Aygun D, Doganaya Z, Nargis C, Incelatin $O$. Retrospective evaluation of emergency service patients with poisoning: A 3-year study. Advances in therapy. 2005;22:650 -8.

10. Gulohglu C, Kara IH. Acute poisoning cases admitted to a university hospital emergency department in Diyarbakir. Turkey. Human and experimental toxicology. 2005;24:4954.
11. Z. Ramesha KN, Rao KB, Kumar GS. Pattern and outcome of acute poisoning cases in a tertiary care hospital in Karnataka, India. Indian J Crit Care Med. 2009;13:152-5.

12. Lohani SP. An epidemiological study of poisoning cases Reported to the Nepal Drug and poison information center, Kathmandu, Nepal Drug and Poison Center.

13. Kafle KK, Nepal MK, Sharma SR, Pokharel RP. Poisoning cases at TU Teaching Hospital. J Inst Med. 1989;11:297301.

14. Suvedi BK. A retrospective study of poisoning cases at Bir Hospital, Nepal. J Inst Med. 1990;12:296-302.

15. Kafle KK, Gyawali KK. Organ phosphorous commonest poisoning agent. J Inst Med. 1992;14:228-33.

16. Poudyal BP. Poisoning: Pattern and Profile of Admitted Cases in a Hospital in Central Nepal. J Nep Med Assoc. 2005;44:92-6.

17. Ghimire RH, Sharma SP, Pandey KR. A Comparative study of Acute Poisoning in Nepal at Tertiary and Secondary Level Hospitals. J Nep Med Assoc. 2004;43:130-3.

18. Gupta SK, Joshi MP. Pesticide Poisoning Cases Attending Five Major Hospitals of Nepal J Nep Med Assoc. 2002;41:447-56.

19. Prasad PN, Karki P. Poisoning cases at TUTH emergency: a one - year review. J Inst Med. 1997;19:18-24.

20. Karki RK, Risal A. Study of Poisoning Cases in a Tertiary Care Hospital. Kathmandu Univ Med J. 2012;10(4):70-3. 